3. Lawton JS, Liu J, Kulshrestha K, Moon MR, Damiano RJ Jr, Maniar H, et al. The impact of surgical strategy on survival after repair of type A aortic dissection. $J$ Thorac Cardiovasc Surg. 2015;150:294-301.e1.

4. Pochettino A, Brinkman WT, Moeller P, Szeto WY, Moser W, Cornelius K, et al. Antegrade thoracic stent grafting during repair of acute DeBakey I dissection pre- vents development of thoracoabdominal aortic aneurysms. Ann Thorac Surg. 2009:88:482-9; discussion 489-490.

5. Stefanov F, Morris L, Elhelali A, Kavanagh EP, Lundon V, Hynes N, et al. Insights from complex aortic surgery with a Streamliner device for aortic arch repair (STAR). J Thorac Cardiovasc Surg. 2016;152:1309-18.e5.
See Article page 770.

\section{Commentary: Is the time for aortic arch redo-surgery running out?}

\author{
Luca Di Marco, MD, PhD, ${ }^{a}$ Alessandro Leone, $\mathrm{MD},{ }^{\mathrm{a}}$ \\ Antonio Maria Calafiore, $\mathrm{MD},{ }^{\mathrm{b}}$ and \\ Michele Di Mauro, MD, PhD, $\mathrm{MSc}^{c}$
}

Despite the fact that open surgical repair still represents the gold standard treatment for complete aortic arch replacement, it continues to be burdened by high mortality and neurologic complications $(5 \%-23 \%$ and 5\%-18\%, respectively), especially for patients who require redo surgery. ${ }^{1-4}$ Therefore, in the era of endovascular surgery, it is not surprising that hybrid operating rooms, new technologies, approaches, and methods are challenging open surgery, trying to replace it. Less-invasive endovascular procedures, used to treat aortic arch diseases, have clear and undoubted advantages over open surgery, especially in redo cases: (1) re-sternotomy is not required; (2) there is no need for cardiopulmonary bypass; and (3) there is no need for hypothermic circulatory arrest and cerebral protection.

There is no doubt that a patient already treated for acute type A aortic dissection (TAAD) continues to have considerable risk for future aortic reintervention and that resternotomy is associated with increased risk for short- and long-term mortality after proximal aortic repair. ${ }^{5,6}$ In the light of these advantages, it is clear how selected high-risk patients with chronic residual TAAD

\footnotetext{
From the a Cardiac Surgery Unit, Cardio-Thoracic-Vascular Department, S. Orsola Hospital, University of Bologna, Bologna; ${ }^{b}$ Division of Cardiac Surgery, Molise Gemelli, Campobasso; and ${ }^{\mathrm{c}}$ Division of Cardiac Surgery, SS Annunziata Hospital, Chieti, Italy.

Disclosures: Authors have nothing to disclose with regard to commercial support.

Received for publication Feb 12, 2020; accepted for publication Feb 14, 2020; available ahead of print Feb 21, 2020.

Address for reprints: Michele Di Mauro, MD, PhD, MSc, Heart Disease Department, SS Annunziata Hospital, Via dei Vestini, 66100, Chieti, Italy (E-mail: mdimauro1973@gmail.com).

J Thorac Cardiovasc Surg 2021;162:779-80

$0022-5223 / \$ 36.00$

Copyright $(2020$ by The American Association for Thoracic Surgery

https://doi.org/10.1016/j.jtcvs.2020.02.060
}

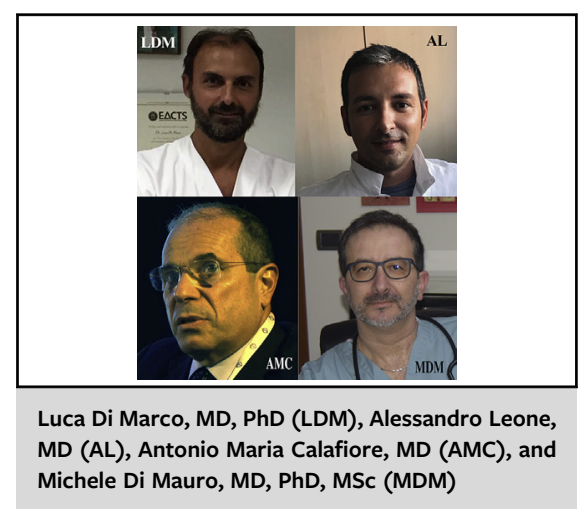

CENTRAL MESSAGE

Is the time for aortic arch redosurgery running out?

could benefit from the endovascular approach, as they often require reoperations to exclude the aortic arch entry tears with consequent enlargement of the pressurized false lumen.

Budtz-Lilly and colleagues ${ }^{7}$ report the current data regarding eligibility for endovascular treatment of dissected aortic arch using an arch inner-branched stent graft, creating the anatomical conditions for a potential further endovascular treatment of the aortic arch and identifying those factors playing a key role in this process. The authors carefully reviewed the angiocomputed tomography scans of the patients operated on for acute TAAD, drawing a picture of eligible candidates for future endovascular arch repair as an alternative to open surgery. Beyond this, the strengths of this study are the very large cohort of patients enrolled, with longer follow-up and the exclusion of those patients with wellknown ineligibility factors such as the presence of a mechanical aortic valve. Another important key point of the study is the different eligibility between those patients in whom distal aortic clamping was used and those in whom 
it was not. In fact, as rightly pointed out by the authors, an open distal anastomosis with hypothermic circulatory arrest may lead to a longer and technically suitable proximal landing zone for future endovascular options for arch repair.

The study shows another factor that could potentially limit a possible endovascular option, the presence of proximal anastomoses, in case of coronary revascularization, can reduce the part of the ascending aorta useful for a proximal landing zone. The authors also show that older age is not associated with noneligibility for a further aortic arch endovascular repair. Finally, this study also confirms that the vast majority of patients requiring further aortic arch repair after surgery for acute TAAD are technically eligible for a further endovascular arch approach. With this awareness, we believe this question is legitimate: is the time for aortic arch redo-surgery running out?

\section{References}

1. Hiraoka A, Chikazawa G, Tamura K, Totsugawa T, Sakaguchi T, Yoshitaka H. Clinical outcomes of different approaches to aortic arch disease. J Vasc Surg. 2015;61:88-95.

2. Englum BR, He X, Gulack BC, Ganapathi AM, Mathew JP, Brennan JM, et al. Hypothermia and cerebral protection strategies in aortic arch surgery: a comparative effectiveness analysis from the STS Adult Cardiac Surgery Database. Eur J Cardiothorac Surg. 2017;52:492-8.

3. de la Cruz KI, Green SY, Preventza OA, Coselli JS. Aortic arch replacement in patients with chronic dissection: special considerations. Semin Cardiothorac Vasc Anesth. 2016;20:314-21.

4. Patel HJ, Nguyen C, Diener AC, Passow MC, Salata D, Deeb GM. Open arch reconstruction in the endovascular era: analysis of 721 patients over 17 years. J Thorac Cardiovasc Surg. 2011;141:1417-23.

5. Gaudino M, Girardi LN, Rahouma M, Leonard JR, Di Franco A, Lau C, et al. Editor's choice-aortic reoperation after replacement of the proximal aorta: a systematic review and meta-analysis. Eur J Vasc Endovasc Surg. 2018;56:515-23.

6. Sandhu HK, Tanaka A, Zaidi ST, Perlick A, Miller CC 3rd, Safi HJ, et al. Impact of redo sternotomy on proximal aortic repair: does previous aortic repair affect outcomes? J Thorac Cardiovasc Surg. 2019;19:1-9.

7. Budtz-Lilly J, Vikholm P, Wanhainen A, Astudillo R, Thelin S, Mani K. Technical eligibility for endovascular treatment of the aortic arch after open type A aortic dissection repair. J Thorac Cardiovasc Surg. 2021;162:770-7. 